Review

\title{
Biocompatibility of Chitosan Carriers with Application in Drug Delivery
}

\author{
Susana Rodrigues ${ }^{1, \dagger}$, Marita Dionísio ${ }^{1, \dagger}$, Carmen Remuñán López ${ }^{2}$ and Ana Grenha ${ }^{1, *}$ \\ 1 Centre for Molecular and Structural Biomedicine (CBME), Institute for Biotechnology and \\ Bioengineering (IBB), Faculty of Sciences and Technology, University of Algarve, \\ Campus de Gambelas, Faro 8005-139, Portugal; \\ E-Mails: susananasus@gmail.com (S.R.); maritadionisio@gmail.com (M.D.)
}

2 Department of Pharmacy and Pharmaceutical Technology, Faculty of Pharmacy, University of Santiago de Compostela, Campus Vida, Santiago de Compostela 15782, Spain;

E-Mail: mdelcarmen.remunan@usc.es

* Author to whom correspondence should be addressed; E-Mail: amgrenha@ualg.pt; Tel.: +351-289-800-100 (ext. 7441); Fax: +351-289-818-419.

$\dagger$ These authors contributed equally to this work.

Received: 26 June 2012; in revised form: 3 August 2012 / Accepted: 21 August 2012 / Published: 17 September 2012

\begin{abstract}
Chitosan is one of the most used polysaccharides in the design of drug delivery strategies for administration of either biomacromolecules or low molecular weight drugs. For these purposes, it is frequently used as matrix forming material in both nano and micron-sized particles. In addition to its interesting physicochemical and biopharmaceutical properties, which include high mucoadhesion and a great capacity to produce drug delivery systems, ensuring the biocompatibility of the drug delivery vehicles is a highly relevant issue. Nevertheless, this subject is not addressed as frequently as desired and even though the application of chitosan carriers has been widely explored, the demonstration of systems biocompatibility is still in its infancy. In this review, addressing the biocompatibility of chitosan carriers with application in drug delivery is discussed and the methods used in vitro and in vivo, exploring the effect of different variables, are described. We further provide a discussion on the pros and cons of used methodologies, as well as on the difficulties arising from the absence of standardization of procedures.
\end{abstract}


Keywords: biocompatibility; chitosan; cytotoxicity; genotoxicity; microparticles; nanoparticles

\section{Introduction}

Micron- and nanosized particles are sophisticated technologies that were developed to answer specific demands in the field of drug delivery, namely addressing the limitations posed by the administration of a new generation of low molecular weight drugs and biomacromolecules [1,2]. Chitosan and its derivatives in the last two decades have proven to be excellent and safe candidates for improving mucosal and trans-mucosal delivery or drugs, mainly due to their mucoadhesive and absorption enhancing properties, closely related with the cationic character of the polymer [3-5]. Indeed, due to its positive charge, chitosan has the special feature of adhering to mucosal surfaces, favoring the interaction of the drug with the mucus layer covering different epithelial surfaces [6-8]. The potential of chitosan for trans-mucosal drug delivery has been further strengthened by extensive demonstrations of its capacity, both in vitro and in vivo, in transitorily widening tight junctions between epithelial cells, thus facilitating the transport of poorly absorbable macromolecules through well-organized epithelia barriers [2,5]. This particular behavior governs the different toxicological patterns between chitosan and conventional absorption promoters, which are known to cause permanent epithelial damage.

In addition to all these positive features, chitosan has been reported to exhibit other relevant properties, including biodegradability and biocompatibility [9-11]. In recognition of all these appealing characteristics, chitosan has been indicated as a promising biomaterial for biomedical and pharmaceutical, i.e., drug delivery, applications. The characterization of its biocompatibility pattern encompasses, therefore, a major issue, as it will drive the process of a future human drug delivery application. Whereas many of the technological applications of chitosan did not require regulatory approval, the use of chitosan in drug delivery, especially in particulate forms, requires significant improvement in documentation regarding the biocompatibility and safety of these products. Despite the outstanding reputation that comes with chitosan, it is true that a number of challenges related to biocompatibility have yet to be met; and some studies seem to raise some doubts concerning its applicability. Additionally, it is often erroneously assumed that the formulation of chitosan as a carrier does not have implications on its biocompatibility.

This review highlights the interest of biocompatibility assessment in the development of chitosan-based carriers for mucosal drug delivery. We provide the contextualization of biocompatibility in the field of drug delivery, presenting the methods used to assess this property and focusing on their advantages and disadvantages. Finally, the difficulties arising from the absence of standardized conditions of assessment are also addressed.

\section{Chitosan Application in Drug Delivery}

Chitosan is one of the most popular materials in the field of drug delivery and is, by far, the most applied of the natural polymers. Its attractiveness relies on very interesting structural and biological properties, which include the cationic character and the solubility in aqueous medium on one side, but 
most importantly, its characteristic biodegradability and mucoadhesivity on the other $[4,6,10,12]$. These properties are a result of the proper structure of the polysaccharide, which is composed of repeating alternated units of $N$-acetylglucosamine and D-glucosamine, linked by $\beta$-(1-4) glycosidic bonds [13], as depicted in Figure 1.

Figure 1. Chitosan structure ( $n$ and $m$ assume different ratios) [14].

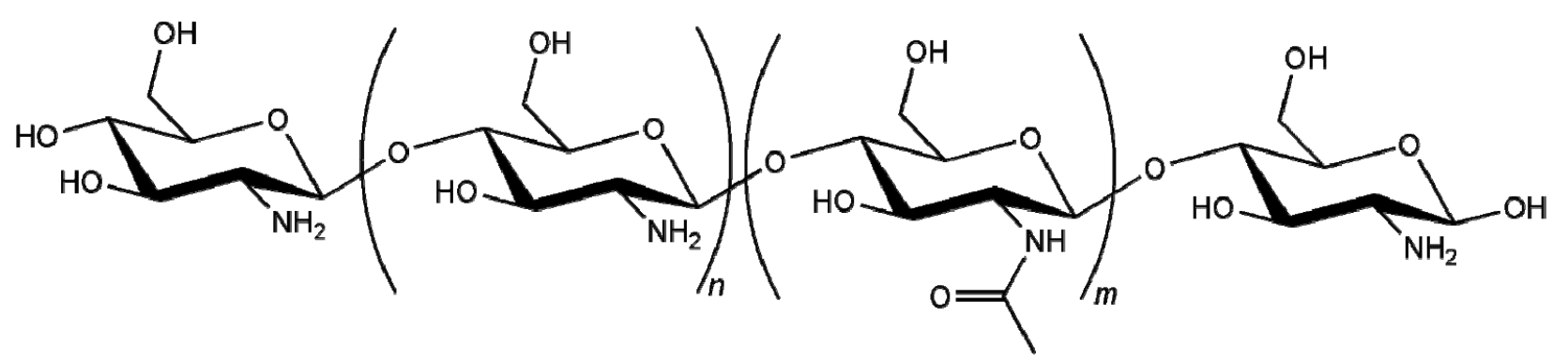

Chitosan is available in a variety of forms that mainly differ in the molecular weight and degree of deacetylation $[15,16]$. These differences affect important characteristics such as solubility and mucoadhesivity [5]. With a $\mathrm{p} K_{\mathrm{a}}$ of approximately 6.5 , chitosan is soluble in acidic solutions owing to the protonation of the amino groups composing the polymeric chain at this $\mathrm{pH}[13,17]$. In this regard, highly deacetylated chitosan $(85 \%)$ is readily soluble in solutions of $\mathrm{pH}$ up to 6.5 , but as the deacetylation degree decreases, the solubilization becomes more difficult [18]. With respect to the mucoadhesive capacity of the polymer, it is reported to increase with the increase in the deacetylation degree, as this provides more positively charged amino groups available for the interaction with negatively charged residues of the mucus, namely sialic acid [19,20]. In fact, this explains why the greatest part of chitosan applications in drug delivery reports the use of highly deacetylated chitosan, as mucoadhesion is responsible for a more prolonged retention in the site of action or absorption.

Applications of chitosan in the field of drug delivery have been mostly focusing on the production of carriers that improve the performance and effectiveness of encapsulated molecules, either macromolecules or low molecular weight drugs [12,21-23]. Nano and microparticles, as solid continuous matrixes, are the most usual carriers with a chitosan-based composition [4,23,24], but nanocapsules have also been reported [19,25]. Importantly, many works report the use of chitosan as a coating material, instead of being a part of the matrix of the system [22,26-28], which is a relevant recognition of chitosan appealing properties. In this respect, the coating of several different core structures has been reported, including solid lipid nanoparticles [26,29], polymeric nano and microparticles [28,30-32] and liposomes [33,34]. The clear objective of such an approach is to modify the surface properties of the core structure, either to improve the pattern of interaction with surrounding structures or to improve the biodegradation profile.

One of the most relevant properties of chitosan, with particular interest in drug delivery, relies on its ability to transiently open epithelial tight junctions. This capacity has been demonstrated on numerous occasions, both in the form of a solution and carrier, resulting in the permeation enhancement of macromolecules through well-organized epithelia such as the nasal [35,36], intestinal [37-39], ocular [40], buccal [41] and pulmonary [42]. Another characteristic of chitosan that increases interest 
in the polymer, is the flexibility of its molecular structure, which facilitates chemical modifications [43] that are performed to further improve several properties such as solubility or mucoadhesion $[23,44,45]$.

Two of the most critical features of drug delivery systems concern their biodegradability and biocompatibility, which are mandatory requisites for acceptance by the regulatory agencies. Biodegradability becomes a crucial feature when considering acute and long-term toxicity, as non-degradable materials may accumulate in organs or even intracellularly [10]. Chitosan has been reported as highly biodegradable, which is mainly due to the fact that, under physiological conditions, its molecular chains can be digested by either lysozyme or chitinase. While the former is reported to exist in mucosal surfaces $[10,11,46]$, the latter is produced by normal intestinal flora $[11,43]$. In addition, when oral delivery is under consideration, the hydrolytic activity of the acidic gastric medium has to be considered as an extra means of chitosan degradation $[11,16]$.

However, the ability of a material to be biologically degraded, although positively understood, must also be considered from the point of view of the possibility of resulting in toxic degradation products [47]. In the case of chitosan, its degradation does not raise any critical concern, as the products of its metabolism are oligosaccharides that are either incorporated into glycosaminoglycan and glycoprotein metabolic pathways or easily excreted in urine directly [48-50]. Furthermore, evidence has been produced in several reports that no issues of accumulation/retention in the body are observed [10]. Nevertheless, if a too rapid degradation occurs, it might result in an accumulation of amino sugars, inducing an inflammatory response and, hence, affecting chitosan biocompatibility [51,52].

All the above mentioned properties of chitosan, from its intrinsic structural properties to the demonstrated mucoadhesive and permeation enhancement capacities, as well as biodegradability, endow this polymer with valuable potential for drug delivery applications. Altogether, these features have been resulting in a tremendously increasing number of publications and patents. The biocompatibility pattern of the polymer and its carriers is obviously of utmost importance to complete the background of relevant properties and to support the potential of chitosan, and will be addressed extensively in the following section.

\section{Biocompatibility of Chitosan Carriers}

As referred to previously, chitosan has been proposed very frequently as a carrier or functional excipient (for instance, as permeation enhancer) in the formulation of active compounds to be delivered [16]. Its biocompatibility is, thus, a current issue of great significance, although the real meaning of the word is many times disregarded. Biocompatibility is frequently addressed as absence of toxicity, but these are different concepts referring to different contexts. In a very elucidative review on the preclinical safety of polymeric carriers, Gaspar and Duncan clearly indicate that while drug molecules should be discussed in terms of toxicity, biomedical materials, which include polymeric materials, should be considered for their biocompatibility. From this perspective, and as depicted in Figure 2, toxicity refers to the potential harm that may be caused by a material, whereas biocompatibility further extends to the detrimental or beneficial effect of the physiological environment on the material performance [53]. 
Figure 2. Illustration of the distinction between "biocompatibility" and "toxicity" [53].

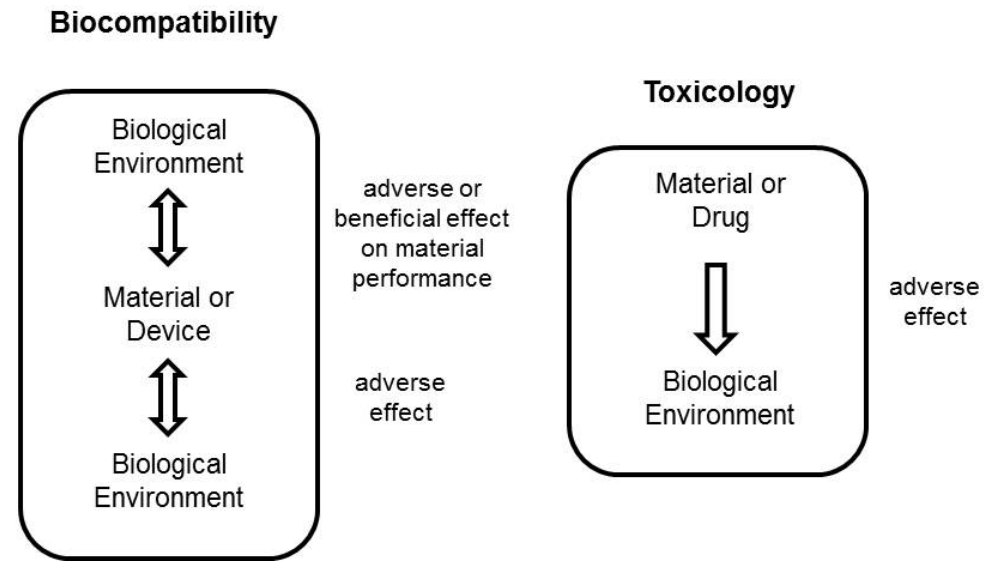

This differentiation appears in the sequence of the first clear definition of biocompatibility agreed at a consensus conference of the European Society for Biomaterials [54] and the recent reformulation of that definition [55]. The first definition, dating from 1987, indicates biocompatibility to be the ability of a material to perform with an appropriate host response in a specific situation [54]. As said, this was recently re-defined to a more complete concept, as being the ability of a biomaterial to perform its desired function with respect to a medical therapy, without eliciting any undesirable local or systemic effects in the recipient or beneficiary of that therapy, but generating the most appropriate beneficial cellular or tissue response in that specific situation, and optimizing the clinically relevant performance of that therapy [55]. This comprehensive definition makes the contextualization of biocompatibility a mandatory requisite and addresses the possibility that materials are often required to specifically interact with the surrounding environment and in many cases with cell structures, instead of being ignored by them. It becomes, therefore, clear, that polymers (as well as polymer-based carriers) cannot be described as biocompatible without the proper contextualization of route of administration, frequency of administration and dose [53].

Actually, biocompatibility is both region- and host-dependent, meaning that different responses might be obtained when evaluating multiple sites or objectives [56]. In this respect, although when studies address these issues, the understanding of materials biocompatibility is hindered by the limited knowledge on the biological processes that are involved in material-cells interactions [56,57]. This is why several high-throughput technologies are being developed and applied to this end, examining global cell-biomaterial interactions in a faster way and addressing important questions such as the pathways and networks involved in cell-material interactions [56].

Almost all works concerning chitosan application refer to the polymer as a non-toxic, biologically compatible material, thus suitable to be used in carrier production in the field of drug delivery. However, although works addressing the biocompatibility of chitosan carriers are becoming more frequent, usually an incomplete set of assays is performed. In other cases, this question is completely disregarded, the authors simply assume polymer biocompatibility and, by affinity, that of the carrier. Sometimes this statement is based on chitosan approval by the American Food and Drug Administration (FDA) as a wound dressing material [16,21], for instance. It is a fact that chitosan is approved for that end and also as a dietary component in several other countries [16]. Nevertheless, and in the sequence of the above mentioned issues concerning the intrinsic definition of 
biocompatibility, chitosan biocompatibility must be addressed in the context of each particular case and condition. Accordingly, the FDA and other regulatory agencies do not approve materials in a general manner, instead evaluating and approving materials with respect to specific applications. In this context, a very important issue that seems to be overlooked on many occasions is that, as happens for many other materials, chitosan exists in several different structures and formulated as different types of carriers for administration in varied conditions. Each entity must, then, be considered separately, requiring specific testing in the particular conditions expected for its administration.

Still in this context, it is not infrequent to find works on the subject of carrier biocompatibility as being solely dependent on that of the material composing its structure. This is an erroneous approach, as several parameters, other than the material itself, are recognized mediators of the biocompatibility, affecting the carrier behavior and determining its clinical outcome; individual characteristics (age, sex, general health), as well as the proper structure of carriers (size, morphology, cristallinity, surface characteristics, degradation profile and products) are included in this list [55]. It is well recognized now that the physicochemical properties of materials can alter dramatically when formulated as specific structures like those of the different carriers, as particular interactions take place and the area available for contact with surrounding environments is modified in each case. Therefore, the carriers may exhibit new and unique biological properties, thus generating potential different risks as compared to the raw materials of the same chemistry [47].

The formulation of chitosan under the form of a carrier may have implications on its biocompatibility and, therefore, it is important to address, and treat differently, both the biocompatibility of chitosan as a molecule and as a carrier. As a positively charged molecule, chitosan usually provides a great interaction with cell membranes, which are negatively charged (approximately $-70 \mathrm{mV}$ ) due to ionic interchanges between the intracellular and extracellular medium, which are mediated by the $\mathrm{Na}^{+} / \mathrm{K}^{+}$pump [58] Actually, owing to that positive charge, chitosan nanoparticles are often taken up by the cells [59]. When chitosan is formulated as a carrier and complexed with a drug, the number of positively charged amino groups that remains available is frequently decreased, comparatively. This lower number of charges consequently affects its capacity to interact either with cell membranes and the surrounding environment, potentially decreasing its uptake and, possibly, potential toxicity. As such, highly deacetylated chitosans have a naturally higher propensity for cell interaction, as has been demonstrated [60].

As previously mentioned, in parallel with the distinction between different chitosan types and the need to address the difference between molecules and carriers, it is of utmost importance that biocompatibility is understood as a contextual concept. This means that references to the biocompatibility of a carrier should be always accompanied by the intended application [55] or, at least, in the case of drug delivery, by the route of administration to be focused.

As the carrier comes in contact with the host, a sequence of events is expected to take place, potentially including carrier-protein interactions, as well as those with other surrounding macromolecules, and also the induction of inflammatory and/or immune responses [55,56]. Therefore, assessing some of these events might give potential indications on the carrier biocompatibility. Many in vitro assays are frequently described to provide the evaluation of carrier biocompatibility, in many cases in accordance with ISO 10993 [61-63], which describes the topics of evaluation and testing relevant for the biological evaluation of medical devices. This standard indicates varied device categories, first dividing them according to the nature of their contact with the body (surface devices, 
external communicating devices and implants). Chitosan carriers as is the focus of this review are included in the category of surface devices. A second division then appears, addressing the contact time that is expected for the specific device with the body. The most basic tests considered for an initial evaluation refer to cytotoxicity, sensitization and irritation or intracutaneous reactivity. Tests should include the evaluation of cellular morphology and membrane integrity, as well as metabolism efficiency [61]. If contact time extends beyond 24 hours, acute or sub-acute toxicity must be also addressed (or even implantation tests, if applicable) [62]. Genotoxicity studies are also covered in the ISO 10993 [63]. The importance of assessing genotoxic effects relies on the fact that materials and carriers might not be cytotoxic, but evidence the ability to affect the genetic information of the cells they are in contact with, for instance leading to abnormal cell growth [64,65]. The standard also specifies that in vitro tests should be repeated several times, not only to ensure the validation of the used analytical methods, but also to address variations occurring in cells [61]. Furthermore, it designates, in certain conditions, a substitution of animal studies by specifically developed in vitro tests and indicates the need to improve animal tests to minimize animal pain and distress [66]. The tests performed using cells are generally devoid of ethical issues and are easier to control and reproduce, being also less expensive in comparison with studies involving animals [64]. Performing the proposed in vitro tests may not determine the final carrier biocompatibility, but will certainly comprise an important step towards animal studies and the final clinical trials. Importantly, performing this set of in vitro assays permits decreasing in vivo testing, thus complying with the requirements of the ISO.

In the following section, assays described in the literature for biocompatibility evaluation of chitosan carriers that are applied in drug delivery are presented.

\subsection{In Vitro Cell Toxicity}

In vitro tests of cell toxicity provide a rough assessment of the ability of cells relevant to a determined application to survive in the presence of specific materials or carriers, the latter being the subject of the present review. In general, two different protocols are observed, one providing a direct contact of the carrier with the cells, and another evaluating the effect of the contact with leachable materials (diffusible components, degradation products, etc.), thus considering an indirect cell contact [57,67].

A very wide number of assay techniques can be used to evaluate cytotoxicity. Table 1 describes those assays reported for the evaluation of chitosan carriers. Whatever the selected test, the generally desired outcome is that cell viability remains close to $100 \%$ after contacting with the tested material/system. Depending on which cellular characteristics are focused, the assays described to evaluate chitosan carriers are mainly divided into metabolic assays and membrane integrity assays. While the former assess occurrences of an early stage of cell death, the latter determine the occurrence of membrane disruption that is more frequent during the later stage of the process [68]. 
Table 1. Summary of in vitro cytotoxicity assays described for the evaluation of chitosan carriers.

\begin{tabular}{|c|c|c|}
\hline Assay & Theoretical principle & Evaluated cellular function \\
\hline Tryplan blue & Blue dye is excluded by viable cells & Cell membrane integrity \\
\hline Propidium iodide & $\begin{array}{l}\text { Red dye enters damaged cells and intercalates DNA, } \\
\text { enhancing dye fluorescence }\end{array}$ & Cell membrane integrity \\
\hline $\begin{array}{l}\text { Lactate } \\
\text { dehydrogenase }\end{array}$ & $\begin{array}{l}\text { LDH leaks from damaged cell membrane. Enzyme } \\
\text { transforms NADH + pyruvate into } \mathrm{NAD}^{+}+\text {lactate: } \\
\text { Direct quantification of NADH at } 340 \mathrm{~nm} \\
\text { Tetrazolium reduction to formazan }\end{array}$ & Cell membrane integrity \\
\hline Neutral red & Lysosomal uptake of red dye in live cells & Lysosomal membrane integrity \\
\hline MTT, MTS, XTT & $\begin{array}{l}\text { Tetrazolium reduction to blue formazan in } \\
\text { metabolically active cells }\end{array}$ & Mitochondrial metabolism \\
\hline Alamar blue & $\begin{array}{l}\text { Resazurin reduction to pink resorufin by metabolically } \\
\text { active cells }\end{array}$ & Mitochondrial metabolism \\
\hline
\end{tabular}

DNA: deoxyribonucleic acid; LDH: lactate dehydrogenase;

MTT: 3-(4,5-dimethylthiazol-2-yl)-2,5-diphenyltetrazolium bromide);

MTS: 3-(4,5-dimethylthiazol-2-yl)-5-(3-carboxymethoxyphenyl)-2-(4-sulfophenyl)-2H-tetrazolium);

NAD: nicotinamide adenine dinucleotide;

NADH: reduced form of nicotinamide adenine dinucleotide;

XTT: (2,3-bis-(2-methoxy-4- nitro-5-sulfophenyl)-2H-tetrazolium-5-carboxanilide).

The cell membrane is a functional barrier, using several mechanisms to control the traffic of substances into and out of the cellular structure. A disrupted cell membrane implies cell death and, therefore, the assays providing the assessment of cell membrane integrity permit the discernment between live and dead cells. The trypan blue assay has been frequently used for this end, relying on the exclusion of the dye by viable cells, which possess intact cell membranes, while damaged cells include the dye because their membranes are no longer capable of controlling molecular permeation [64,69-71]. A viable cell thus exhibits a colorless cytoplasm, whereas a damaged one has a blue cytoplasm that is easily identified by microscopic observation, as is evidenced in Figure 3 [64,69,72]. Notwithstanding the easiness of the procedure, this assay has been referred as imprecise, leading to an overestimation of cell viability [69].

Propidium iodide, a red dye, is also used to indicate membrane disruption. It is membrane-impermeable owing to two positive charges existing in its structure [73], but it enters the cells when membrane damage occurs. It has a strong ability to intercalate DNA and registers a strongly enhanced fluorescence upon binding to nuclei acids, the fluorescence change being proportional to the number of damaged cells [64]. At an excitation of $488 \mathrm{~nm}$, it gives a bright signal easily detected and quantified by flow cytometry. One of the problems with this assay is that the intercalation is reversible, so that the dye might leak out from cells that were dead before fixation and stain the previously viable cells [73]. 
Figure 3. Illustration of the result of the Trypan blue exclusion assay on cell culture. Cells including trypan blue (dead cells) are stained in blue and marked with arrows. Adapted with permission from [74].

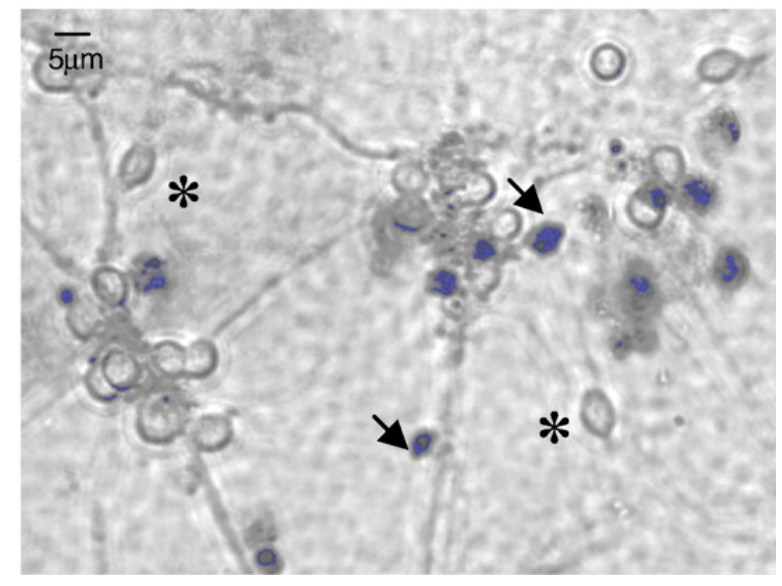

Alternatively, an assay based on the determination of the amount of lactate dehydrogenase (LDH) that is leaking through a damaged cell membrane has also been used [70]. This enzyme is present in cell cytosol and catalyzes the reaction that transforms $N A D H+$ pyruvate into $N A D^{+}+$lactate. The increase of LDH activity in cell culture medium is proportional to the number of lysed cells. Two different protocols can be followed for the quantification of LDH. On one side, NADH can be directly quantified by spectrophotometry at $340 \mathrm{~nm}$ and its amount used to determine LDH level if the reaction starts with known levels of NADH and pyruvate [75]. On the other side, the most common approach uses commercial quantification kits based on a colorimetric assay. In these kits, the formation of $\mathrm{NADH}$ can be measured in a reaction where the tetrazolium salt INT is reduced to formazan, which is a colored substance. The amount of formazan is determined directly by spectrophotometry at $490 \mathrm{~nm}$ and proportionally correlates with the amount of LDH and, consequently, with the number of damaged cells [64]. The loss of intracellular LDH and its release into the culture medium is an indicator of irreversible cell death due to cell membrane damage [76,77].

The neutral red assay is one of the most frequently used, but it evaluates lysosomal membrane integrity rather than cell membrane integrity [71]. This assay is based on the principle that living cells are able to capture the dye, storing it in the lysosomes [64,67]. The efficiency of neutral red retention depends both on the $\mathrm{pH}$ of the lysosome and its membrane proton pump, which maintains the acid environment of the lysosomal compartment. Therefore, lysosomes in unstressed cells are able to retain the dye for longer periods and a destabilization of lysosomal membrane results in leaking of neutral red to the cytosol, decreasing the amount of dye retained in the cells. Neutral red is quantified by spectrophotometry at $540 \mathrm{~nm}$ [78].

Metabolic assays are also of widespread application, generally focusing the mitochondrial metabolism. A reduction of cellular metabolic activity is generally accepted as an early indicator of cellular damage. The most common assay, among all those evaluating cytotoxicity, belongs to this category and is the MTT test (uses the compound 3-(4,5-dimethylthiazol-2-yl)-2,5-diphenyltetrazolium bromide), which comprises the production of a dye by cells with active mitochondrial activity. This assay specifically evaluates an enzyme function, as the yellow tetrazolium salts are reduced to water-insoluble purple-blue formazan crystals by mitochondrial dehydrogenases. These crystals 
precipitate in the cytosol and are then solubilized after the induction of cellular lysis by a surfactant, enabling the absorbance to be read at $540 \mathrm{~nm}[67,76]$. Variants of the assay include the MTS (3-(4,5-dimethylthiazol-2-yl)-5-(3-carboxymethoxyphenyl)-2-(4-sulfophenyl)-2H-tetrazolium) and XTT (2,3-bis-(2-methoxy-4-nitro-5-sulfophenyl)-2H-tetrazolium-5-carboxanilide) assay, which present the advantage of avoiding the solubilization step required in the MTT [64]. In all these assays, a dysfunction of mitochondrial activity is used as a sensor of disturbed cell function. A higher concentration of the dye relates to a higher amount of metabolically active cells, which is usually interpreted as higher cell viability. In some cases, this interpretation should not be as linear as it is taken generally, as the contact with a metabolic inhibitor would have the same effect without actually causing cell death.

Alamar blue assay also falls in the category of MTT, using the same oxidation-reduction principle. The blue coloured agent contains resazurin that is reduced to pink resorufin by metabolically active mitochondria, being then quantified by fluorimetry with excitation at $545 \mathrm{~nm}$ and emission at $590 \mathrm{~nm}[71,79]$. In both MTT (or variants) and Alamar blue assays, the reduction has been believed to be mediated solely by mitochondrial enzymes. However, some works have been suggesting that other enzymes present in the cytosol and microsomes can have a contribution to the reduction reaction [80,81].

Chitosan carriers have been frequently tested by means of the above mentioned assays, with a predominance of the MTT assay, not only using the original polymer [30,82-84], but also chitosan derivatives $[85,86]$. In some cases, a comparison is performed between chitosan solutions and chitosan carriers. In many works, however, the isolated effect of materials composing the matrix of drug delivery systems or that of drug-loaded carriers is not tested, the evaluation being performed only on empty carriers. In these cases, it is not possible to determine rigorously the systems behavior, because a material may not cause cell injury but kill an animal due to its drug release pattern [57]

When analyzing the available studies reporting the assessment of chitosan carriers' biocompatibility, one easily observes that a huge variety of conditions are applied. Even if focusing specifically on the works related with drug delivery, a large number of different cells are used, varied material concentrations are applied, considering different contact times. In addition, the intrinsic variations provided by chitosan as a polymer cannot be disregarded (chitosan as a base or salt, different salts, molecular weight, deacetylation degree, etc.), not to mention that very different carriers are also available. To make the subject even more difficult, different assays are used that evaluate distinct aspects of cellular toxicity. This obviously translates into a wide range of responses that are practically impossible to compare, due to unstandardized conditions of assessment.

Nevertheless, taking into account the overall information made available by the literature, it seems possible to say that the general trend indicates that in many cases chitosan solutions exhibit a certain degree of toxicity that is mostly dependent on the dose $[60,87]$. This confirms a fundamental principle of toxicology, first expressed by Paracelsus, saying that "The dose makes the poison". Apart from depending on the dose, toxicity was also conditioned by the polymer characteristics, such as molecular weight and degree of deacetylation $[60,88]$, as well as by the $\mathrm{pH}$ of the incubation medium and time of incubation $[89,90]$. In turn, it is also observed that when the polymer is used as matrix material of drug delivery systems, in most cases there is no overt toxicity in concentrations ranging up to approximately $1 \mathrm{mg} / \mathrm{mL}$, although higher concentrations have been occasionally referred to not decrease cell viability as well $[28,30,60,84,91-93]$. However, the effect is still governed by the used dose $[60,90,94]$. 
Figure 4 provides examples of very low toxicity of different chitosan carriers determined using metabolic assays.

Figure 4. (a) Cell viability of chitosan/tripolyphosphate nanoparticles in Calu-3 cells (bronchial epithelial cells) determined by MTT assay (top graphic); and (b) chitosan/carrageenan nanoparticles in L929 cells (fibroblasts) determined by MTS assay (bottom graphic) [84,91].

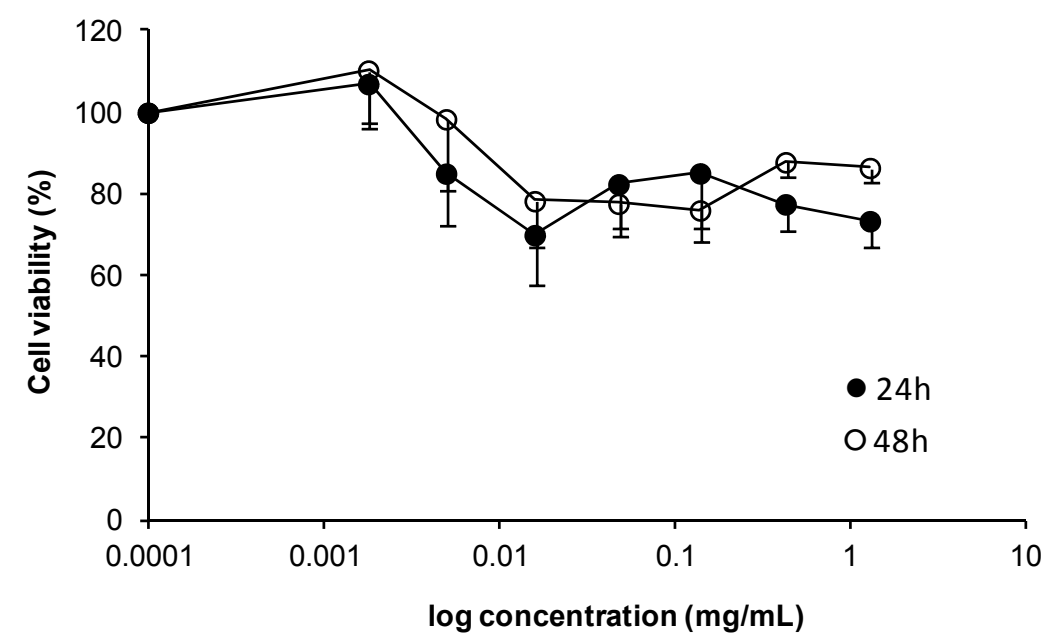

(a)

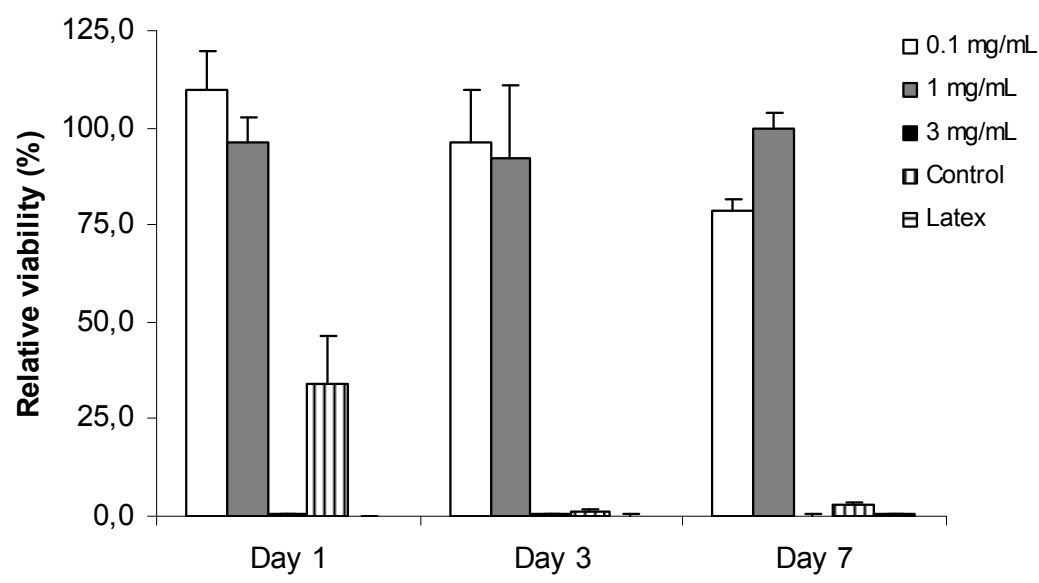

(b)

The different behaviors observed between chitosan molecules and carriers might be explained by the distinct conformation that molecular chains adopt when formulated as carriers, which does not allow the exposure of many of the groups responsible for interaction when in solution. Nevertheless, there are also works reporting a similar cytotoxic pattern for both chitosan solutions and particles [60].

This discrepancy of results is unfortunately observed in the literature and is attributed to the previously referred multitude of assay conditions that are used, not only focusing different structural materials and cells, but also in what concerns the general specificities of the assays. In the cases where chitosan is combined with other polymers to compose the systems' matrix, the selected secondary polymer naturally affects the overall cytotoxicity of the carrier [95,96].

Many works also report the use of chitosan as a coating material $[28,87,97,98]$. These approaches can endeavor to achieve different outcomes, from an increased mucoadhesion, an enhancement of the 
biocompatibility profile by surface modification, or a general improvement in the formulation performance. Whatever the objective, the final biocompatibility of the system will obviously depend on its total composition. In this regard, it has been generally reported that no important toxicity is observed when chitosan is coating a specific core $[87,97,99,100]$ or an improvement of the overall toxicity is obtained due to the presence of the polysaccharide $[28,96,98]$.

One important question that is worth mentioning is that, whatever the selected assay, the samples incubated with the cells should be sterile, to avoid cell contamination and a misjudgment of cytotoxicity. It is further considered that conducting multiple tests, addressing distinct aspects of cellular function, is advantageous to ensure that valid conclusions are drawn, permitting a higher confidence on the observations [64]. An example of this strategy is evidenced in Figure 5, in this case with an observation of some differences in the quantification of cell viability, which are attributed to different sensitivities of the used tests.

Figure 5. Comparison between the viability of A549 cells after incubation with different formulations of chitosan/PLGA nanoparticles $(0.9 \mathrm{mg} / \mathrm{mL})$ as determined by MTT and ATP assays [101].

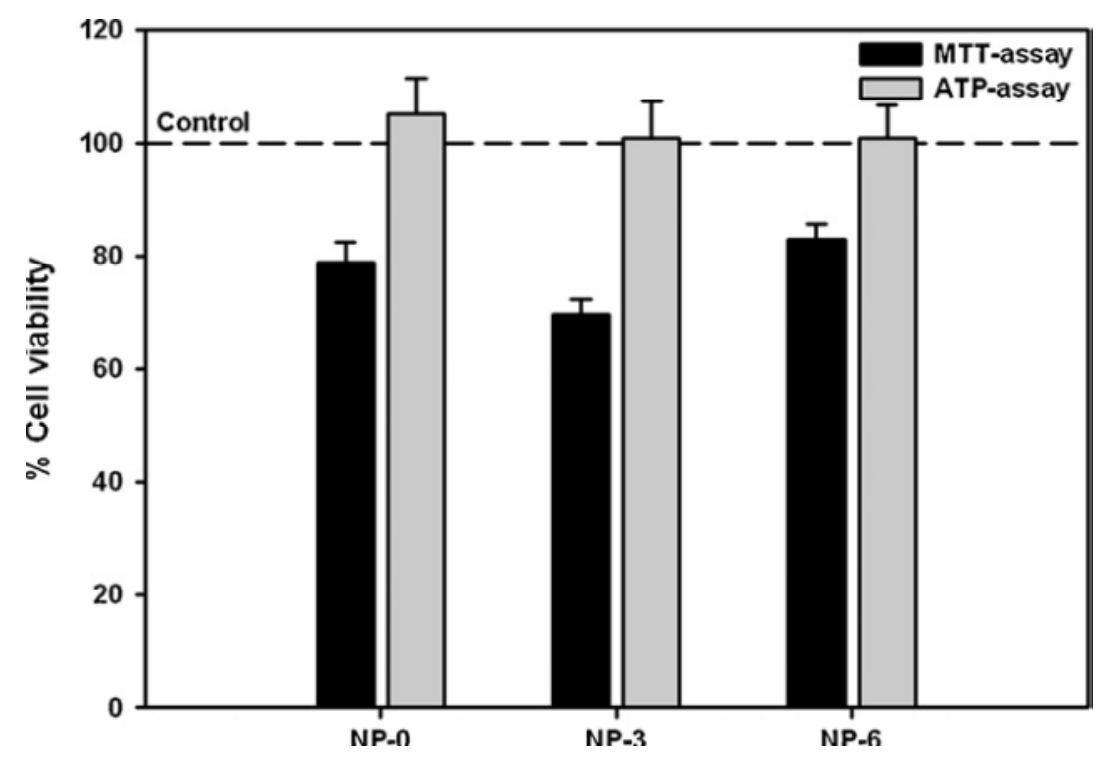

\subsection{In Vitro Detection of Impaired Cell or Epithelial Function}

Although in some cases a toxic effect can result in cell death, there are many other subtler outcomes that do not cause sufficient harm to induce cell death, instead interfering in the normal functions or generating cellular irritancy or stress. In this context, several assays permit the monitorization of cell function. The assays performed in the ambit of the evaluation of chitosan carriers are described in Table 2.

The adenosine triphosphate (ATP) assay assesses the functional integrity of cells, as cell injury results in a decrease of cytoplasmic ATP. ATP plays an important role in energy exchange in biological systems, serving as the principal immediate donor of energy and being present in all metabolically active cells, as any specialized function will demand the use of energy. ATP level can be determined by a luminescent assay in which an enzyme, luciferase, is used to catalyze the formation of light from ATP and luciferin. The emitted light intensity is determined and linearly related with the 
ATP concentration [101,102]. This assay is much more recent than others and, therefore, its use is not widespread. Works reporting its application indicate no alterations in ATP intracellular levels, both upon incubation with chitosan solution [103] and chitosan-based (polylactide-co-glycolide/chitosan) carriers [101]. This latter example is depicted in Figure 5.

Table 2. In vitro cell function and genotoxicity assays described for the evaluation of chitosan carriers.

\begin{tabular}{lll}
\hline Assay & Theoretical principle & Evaluated cellular function \\
\hline \multirow{2}{*}{ ATP } & $\begin{array}{l}\text { Reduction in ATP cytoplasmic level indicates cell injury } \\
\text { Luciferase catalyses light formation from ATP and } \\
\text { luciferin. Luminescence observation }\end{array}$ & Cell functional integrity \\
TER & $\begin{array}{l}\text { Cellular damage or stress induces TER decrease } \\
\text { Electrophoresis separation of broken DNA strands which } \\
\text { fomet }\end{array}$ & Cell barrier integrity \\
& observation by fluorescence microscopy & DNA damage \\
\hline
\end{tabular}

ATP: adenosine triphosphate; DNA: deoxyribonucleic acid; TER: transepithelial electrical resistance.

Chitosan carriers are often proposed in the ambit of systemic mucosal delivery of drugs, which means that the transported drug is expected to permeate an epithelial barrier and enter the blood circulation to be systemically distributed. Drug permeation through the transcellular pathway is dependent on several physicochemical properties of the drugs, namely on their lipophilicity. In turn, mucosal epithelia are generally characterized by the existence of a tight cell barrier, which evidences tight junctions between adjacent cells, so that the free diffusion of molecules by the paracellular route is prevented [104-106]. The intensity of the tightness of these junctions can be determined in cell cultures by a parameter called transepithelial electrical resistance (TER), which provides a measurement of the epithelial barrier properties and integrity [107-109]. TER has been pointed frequently as a sensitive marker for cellular damage, indicating sub-lethal toxicity $[67,101,110]$ and any alteration in TER suggests a change in the epithelial barrier function [110]. Chitosan is known to have the ability to transiently open epithelial tight junctions, permitting an increase of drug permeation by acting as an absorption promoter. The mechanism underlying chitosan effect relies on the interaction of its protonated amino groups with cell membranes. This interaction produces a reversible structural reorganization of junction proteins, encompassing a specific redistribution of cytoskeletal F-actin and the tight junction protein ZO-1, which results in the junction opening [4,111]. With such an ability, chitosan and chitosan carriers have been frequently reported to improve the mucosal absorption of drugs through roughly all the routes of administration, contributing to increased bioavailability $[21,22,87,112,113]$. However, by the proper concept of permeation improvement by the mentioned mechanism, chitosan interferes with the normal barrier function of the epithelia. What makes this alteration acceptable is its non-permanent character, as the opening of tight junctions is known to be reversible when the contact with the polymer or the carriers is ceased $[4,114-116]$. An example of this effect is depicted in Figure 6, using chitosan/cyclodextrin nanoparticles.

In the majority of works it is reported that the decrease of TER induced by chitosan is more pronounced for chitosan solutions than for chitosan carriers, which has been attributed to the fact that in the carriers there are less chemical groups exposed that are available for an interaction with cell 
surfaces, as compared with the polymer chains available in solution [117,118]. However, in some studies it has been observed that nanoparticles produced a more accentuated decrease of TER than solutions [116]. One possible explanation for these different observations is the fact that the carriers/solutions are in contact with the cells in media of different $\mathrm{pH}$. As chitosan $\mathrm{p} K_{\mathrm{a}}$ is around 6.5, the polymeric chains in solution or the carriers will form (or not) aggregates in dependence of the final $\mathrm{pH}$ of the medium they are incubated in. These aggregates will have different sizes, which promote different patterns of contact with the cells.

Figure 6. Effect of chitosan/cyclodextrin nanoparticles $\left(40 \mu \mathrm{g} / \mathrm{cm}^{2}\right)$ on the TER of Calu-3 cell monolayers at $\mathrm{pH}$ 6.4. Each point represents the mean $\pm \mathrm{SD}(n=5)$. Keys: (०) control HBSS pH 7.4; $(\Delta)$ control HBSS pH 6.4; ( $\mathbf{\Delta})$ chitosan/sulfobutylether- $\beta$-cyclodextrin/ tripolyphosphate $(4 / 3 / 0.25)$ nanoparticles; $(\diamond)$ chitosan/carboximethyl- $\beta$-cyclodextrin/ tripolyphosphate (4/4/0.25) nanoparticles; dotted line (----) represents the start of the reversibility experiment [115].

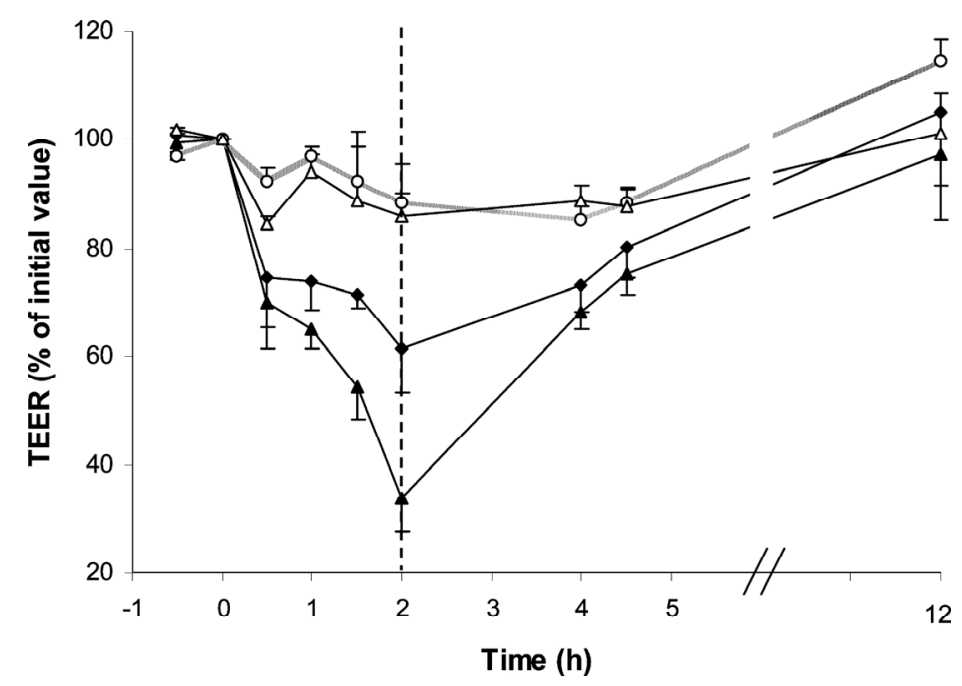

If considered that TER can be used to indicate alterations of cell function, as already explained, it is obvious that chitosan carriers evidence that effect. However, the demonstration that the effect is reversible, permitting a complete recovery of the cellular function upon removal of the stressing agent, is also a remarkable outcome. Although these observations cannot be used to say that chitosan carriers are biocompatible, the reversibility of the effect on the barrier integrity makes it being acceptable.

\subsection{In Vitro Genotoxicity}

Genotoxicity assays provide an examination of the ability of chitosan carriers to damage cellular DNA upon contact with the cells. The most used test is called the comet assay (Table 2), which assays the DNA damage in individual cells using gel electrophoresis [64]. The cells are exposed to an electric field to attract the broken and negatively charged DNA to the anode. After that separation, a fluorescent dye is used to stain DNA, like propidium iodide. Afterwards, the gel is read and cells appear distributed as comets, with intact DNA residing in the head and broken DNA migrating to form the tail. The extent of the tail gives an indication on the number of DNA strand breaks [64,119]. 
Genotoxic evaluation of chitosan carriers is not frequent and a very scarce number of works are available. Chitosan oligosaccharides and a low molecular weight chitosan indicated an absence of genotoxicity in lymphocytes [120]. In a work with chitosan-coated silver nanoparticles proposed as an alternative to conventional antibiotics, the comet assay revealed that a concentration of nanoparticles of $3 \mathrm{ppm}$ does not elicit a genotoxic effect on mouse macrophages (RAW264.7 cells). In contrast, $20 \mathrm{ppm}$ of the nanoparticles induce the formation of a comet with a considerable tail [82].

\subsection{In Vitro Monitorisation of Inflammatory Response}

The development of an inflammatory response as a result of cell contact with carriers has also been used as an indicator of biocompatibility. Testing this hypothesis encompasses the quantification of the release of various inflammatory markers, namely the cytokines IL-6, IL-8 and the tumor necrosis factor (TNF)- $\alpha$. While IL-8 is a chemotatic agent for inflammatory cells, IL-6 is responsible for neutrophil activation and TNF- $\alpha$ is an acute inflammatory response cytokine [121]. A limited number of works dealing with chitosan carriers for drug delivery applications refer to this evaluation. PLGA-CS nanoparticles demonstrated to not induce an increase in any of these inflammation markers upon incubation with Calu-3 cells in nanoparticle concentrations up to $0.2 \mathrm{mg} / \mathrm{mL}$ [96]. Chitosan microspheres encapsulating PLGA nanoparticles generally evidenced no ability to increase TNF- $\alpha$ secretion by RAW264.7 cells (macrophages) in concentrations up to $1.6 \mathrm{mg} / \mathrm{mL}$ [28]. The same cell line evidenced an absence of effect on the levels of IL-6, IL- 8 and TNF- $\alpha$ mediated by the presence of chitosan-DNA nanoparticles up to $24 \mathrm{~h}$, even at the higher nanoparticle concentration tested $(60 \mu \mathrm{g} / \mathrm{mL})[122]$.

As described for other tests, the highest limitation in performing a comparison of results lies in the variety of conditions, in this particular case most related in the wide range of concentrations tested. Interestingly, from concentrations as low as $0.06 \mathrm{mg} / \mathrm{mL}$ to much higher values $(1.6 \mathrm{mg} / \mathrm{mL})$ the observation remained very similar and reported no ability of the tested carriers to induce inflammatory responses.

\subsection{In Vivo Studies}

In vivo studies are essential for the final establishment of biocompatibility. Even when assuming that in vitro cell studies reflect the in vivo observations considering the same cells, it cannot be forgotten that in cell cultures only a few of the in vivo variables are accounted for, thereby not permitting a real simulation of the in vivo environment. In addition, cell cultures are very sensitive to environmental changes, such as temperature, $\mathrm{pH}$ and nutrient concentrations, demanding a confirmation of observations in an in vivo setting [64]. As critically pointed out in a recent review addressing the biocompatibility of drug delivery systems, a carrier may not cause any tissue injury at all, but kill an animal either from drug release or from problems related with intravascular coagulation, embolic events, chelation of ions vital to homeostasis, etc. [57]. This actually means that, although not directly cytotoxic, the carrier (as any material) can induce a destructive reaction thereafter [57], which makes in vivo assays mandatory and determinant after a certain moment and, definitely, well before any attempt of claiming for a human application of the developed carrier. This ambitious step needs to be accounted for regarding both the carrier effectiveness and safety. 
Chitosan biodegradability represents a step forward concerning safety requirements, as it prevents its accumulation in the organism. As mentioned in Section 2, chitosan of suitable molecular weight is said to be directly cleared by the kidney, while that of excessive molecular weight is first degraded into fragments that undergo renal clearance afterwards [11,21]. As previously observed in some in vitro tests, chitosan carriers present a decreased toxicity profile as compared with the corresponding polymeric solutions, because the interaction pattern with cellular structures is different between free polymeric chains and the carriers. The same observation applies, in some cases, to the comparison between loaded and unloaded chitosan carriers. In fact, the loading of a carrier with a drug might cause surface alterations on the carrier, for instance at the level of its surface charge. Some works report that drug loading produces a charge decrease, thereby modifying the interactions with cells and the microenvironment, often leading to decreased toxicity [16]. However, the previous observation that drug release by itself can cause acute toxicity, depending on the release pattern, cannot be disregarded.

There are mainly two different in vivo studies that have been used to assess the biocompatibility of chitosan carriers. By one side it is important to observe histopathological effects resulting from the contact with the carrier. In turn, it is also relevant to determine the inflammatory response induced by the carrier, which is monitored by the determination of several pro-inflammatory cytokines. Additionally, the appearance of relevant alterations in normal clinical signs (diarrhea, fever or other systemic symptoms) is frequently monitored. In what concerns the evaluation of chitosan carriers, there is a high incidence in the assessment of both the oral and the pulmonary routes, but others have also been approached.

The $\mathrm{LD}_{50}$ of paclitaxel-loaded chitosan micelles administered intravenously to mice was $72.16 \mathrm{mg} / \mathrm{kg}$. Moreover, intravenous administration to rabbits did not induce histophatological effects at a dose of 6 $\mathrm{mg} / \mathrm{kg}$ /day during 3 days [123].

For the administration of carriers through the lung route, several different observations were performed using different particles. Chitosan-graft-spermine/pDNA nanoparticles administered to mice using a nose-only device revealed an absence of detectable damage. The histopathological evaluation of the lungs evidenced absence of necrosis, metaplasia, anaplasia in pneumocytes, atelectasis or emphysema. Capillary vessels within the alveolar wall were not enlarged and damaged endothelial cells were rarely observed. Neither congestion nor hemorrhage was noticeable, along with an absence of infiltration of inflammatory cells. In addition, abnormal features were not detected in other major organs (brain, heart, lung, liver, kidney and spleen) [124]. In contrast, the intratracheal administration of glycol chitosan/cholanic acid nanoparticles to mice $(2 \mathrm{mg} / \mathrm{kg})$ induced mild inflammation. Transient neutrophilic pulmonary inflammation was observed from $6 \mathrm{~h}$ to 3 days after administration and the lung expression of pro-inflammatory cytokines (IL-1 $\beta$, IL-6, and TNF- $\alpha$ ), as well as that of the chemokine MIP-1 $\alpha$, increased during the first $24 \mathrm{~h}$, recovering to normal levels thereafter [125]. A more pronounced inflammatory effect was detected upon intratracheal administration to rats of unloaded chitosan microparticles ( $2-10 \mathrm{mg} / \mathrm{kg}$ of particles). A dose-dependent pro-inflammatory effect was manifested by increased levels of bronchoalveolar lavage fluid protein, lactate dehydrogenease activity and increases in lung tissue myeloperoxidase activity and leukocyte migration. A cytological examination of bronchoalveolar fluid further evidenced a large infiltration of neutrophils, which are inflammatory cells [126]. Unfortunately, the authors did not include any group of animals examined sometime after the inhalations, to verify whether a recovery from the inflammation occurred. 
It is also noticeable that in the latter work the used dose varied from 2 to $10 \mathrm{mg} / \mathrm{kg}$, while the previous one only assessed a dose of $2 \mathrm{mg} / \mathrm{kg}$. Obviously the different composition of the particles in both works has a great impact on the observed response, apart from the fact that the former work assesses nanoparticles, while the latter tests microparticles. However, it is important to mention that chitosan microparticles administered at the dose of $2 \mathrm{mg} / \mathrm{kg}$ induced a response similar to that of the control in practically all the assayed parameters [126], thus being considered to not induce an inflammatory response. When comparing both systems assessed at the same concentration ( $2 \mathrm{mg} / \mathrm{kg})$, a similar absence of inflammatory effect was determined.

For the oral administration varied responses were also reported. An evaluation of the hepatotoxicity of 3 doses $(125 \mathrm{mg} / \mathrm{kg}$ each dose) of unloaded alginate/chitosan microparticles administered to guinea pigs spaced by 10 days, revealed no toxic effect by measurement of the indicators of liver function serum bilirubin, alanine aminotransferase and alkaline phosphatase [127]. Unloaded chitosan/poly- $\gamma$-glutamic acid nanoparticles were reported to not induce significant toxicity upon oral administration of a daily dose of $100 \mathrm{mg} / \mathrm{kg}$ for 14 days. As compared to untreated animals, there was no evidence of different clinical signs. In addition, no pathological changes in liver, kidney and intestinal segments were observed [128]. The ability of these nanoparticles to induce hepatotoxicity was also verified by monitoring alanine aminotransferase and aspartate aminotransferase. No alteration in the parameters was obtained after the administration, nor was a histological effect observed [129]. Trimethyl chitosan oligomer/DNA nanoparticles administered orally twice a week during 4 weeks, caused slight diarrhea at 3 weeks in animals treated with $0.5 \mathrm{mg} / \mathrm{mL}$ of nanoparticles (containing $0.1 \mathrm{mg} / \mathrm{mL}$ DNA), which was relieved upon stopping the administration [130]. This was considered very mild toxicity.

A very small increase of serum cytokine levels (IL-2, IL-6, IL-12, TNF- $\alpha$ ) was observed upon administration of chitosan and polyethylenelglycol-coated PLGA nanoparticles $(20 \mathrm{mg} / \mathrm{mL})$ to mice, which completely recovered to normality at $6 \mathrm{~h}$ [131]. Chitosan reduced gold nanoparticles demonstrated a very high $\mathrm{LD}_{50}$ (greater than $2000 \mathrm{mg} / \mathrm{kg}$ ) after administration to rats for a 28 day period. No significant changes were detected in clinical signs, body weight, food consumption, hematological parameters, organ weights or histopathological aspects [132].

Although occasionally some augmented inflammatory response has been reported, the general trend seems to be that no important toxicity or only minimal toxic effects are generated by the administration of chitosan-based carriers. This might be a significant indicator of chitosan safety, but ascertaining the specific conditions to be established in each administration modality and, somehow, provide a standardization of the procedures, remains the most important issue.

\section{Conclusions and Expert Opinion}

Biocompatibility is not a simple interaction between one material and one cell type, but may instead involve degradation products, separate effects from drug and carrier, as well as numerous cell types that present themselves at different times. Therefore, mitigating problems with biocompatibility is rather challenging as, apart from the material properties, poorly understood drug- and material-tissue interactions are also involved. Carriers are also becoming increasingly complex, composed of multiple materials, demanding the need to find components that may yield any toxic influence on the carrier as 
a whole. In turn, as immune reactions are so complex and individual, the biocompatibility of a carrier cannot be adequately described only by taking into account a single type of cell or tissue.

The most common assays testing biocompatibility of chitosan carriers are in vitro cytotoxicity assays, which are usually performed for short periods, rarely going beyond $96 \mathrm{~h}$ and in most cases remaining in the 12-24 h or even less. As a result, these assays only measure finite effects on cells during the first hours after exposure to toxic substances. After contact with a toxic or stressing agent, the cells either recover from, or succumb to, the induced injury. Therefore, in addition to the typical protocol of cytotoxicity evaluation that includes cell incubation with the carrier and an immediate measurement of the parameter being tested, it would be useful to remove the carrier and permit cell incubation with culture medium for a certain period, for instance 24 or $48 \mathrm{~h}$, before performing the cytotoxic evaluation. The ISO 10993 [61-63] gives a good indication of the type of tests that should be considered initially, indicating that an early test of carrier toxicity might avoid expensive and undesirable development work. However, the assertive evaluation of toxicity will only be possible when standard conditions are implemented, so that all reported results converge from well-defined assay settings. In this way, comparing the panoply of results would be a much more accurate and facilitated process and higher benefit would be taken from the produced data.

Another important aspect is that most of the conducted studies are performed in immortalized cell lines but, at least after obtaining satisfactory toxicity profiles, it would be important to repeat those studies in primary cell cultures, as these closely resemble the in vivo environment and are, therefore, more realistic [133]. Different sensitivity has been observed between primary and established cell lines [37,38] and, although primary cell cultures are more difficult to establish, they register variability among different donors, which will contribute to the similarity of in vivo situations, where inter-individual variability is also observed. In summary, the in vitro studies of biocompatibility should assess both the carrier and the drug and, when necessary, the individual components of the carrier. Furthermore, different cells lines, as well as primary cell cultures, should be used with adequate time periods and likewise incubation/recovery protocols, tested.

Notwithstanding the importance of in vitro testing at the initial stage of evaluation of a determined carrier, it is known that the resulting findings frequently lack predictive value of in vivo occurrences. In vivo assays therefore become essential. As mentioned for the in vitro studies in cell culture, a wide variety of assay conditions is also observed in in vivo tests. This disparity focuses not only the performed tests, but also the protocols of each test. Some authors assess the loaded carriers, while others test unloaded particles. Different media are used to suspend the particles, when applicable. Some authors monitor the animals for a certain period after the last administration, in order to assess the reestablishment of normal functions; while others do not assess this possibility. Therefore, once again a standardization of procedures would be helpful and essential to allow advancements in the evaluation of chitosan carriers.

As previously mentioned, chitosan is available in a wide range of different characteristics (molecular weight, deacetylation degree, several different chemical derivatives). It must be, then, recalled that different polymeric characteristics might result in structurally different carriers and, consequently, in diverse responses in vitro and in vivo. Therefore, different carriers and raw materials should be tested accordingly. Considering the available literature on the subject as a whole, chitosan carriers have generally demonstrated to not exhibit overt toxicity, but actually neither nanoparticles nor 
microparticles can be seen as inert. Microparticles are generally taken up by macrophagic cells very easily, thus having the potential to initiate an inflammatory reaction. In turn, the biological consequences of nanoparticle interactions are not well understood so far, but they should be addressed cautiously, considering their ability to gain a size-dependent access to intracellular compartments [57]. Nevertheless, it is interesting to observe, for instance, that chitosan microparticles (around $150 \mu \mathrm{m}$ ) received approval as a support for the growing of fibroblasts [134], an observation that reinforces evidence of chitosan potential.

\section{Acknowledgments}

The authors acknowledge national Portuguese funding through FCT-Fundação para a Ciência e a Tecnologia, project PTDC/SAU-FCF/100291/2008 and PEst-OE/EQB/LA0023/2011, as well as financial support from Spanish Government (PN de I+D 2008-2011, ISCIII-Subdirección General de Evaluación y Fomento de la Investigación, Acción Estratégica de Salud, Project PS09/00816).

\section{References}

1. Antosova, Z.; Mackova, M.; Kral, V.; Macek, T. Therapeutic application of peptides and proteins: Parenteral forever? Trends Biotechnol. 2009, 27, 628-635.

2. Grenha, A.; Carrión-Recio, D.; Teijeiro-Osorio, D.; Seijo, B.; Remuñán-López, C. Nano- and micro-particulate carriers for pulmonary drug delivery. In Handbook of Particulate Drug Delivery; Ravi Kumar, M.N.V., Ed.; American Scientific Publishers: Valencia, CA, USA, 2008; Volume 2, pp. 165-192.

3. Peppas, N.A.; Thomas, J.B.; McGinity, J. Molecular aspects of mucoadhesive carrier development for drug delivery and improved absorption. J. Biomater. Sci. Polym. Ed. 2009, 20, 1-20.

4. Amidi, M.; Mastrobattista, E.; Jiskoot, W.; Hennink, W.E. Chitosan-based delivery systems for protein therapeutics and antigens. Adv. Drug Deliv. Rev. 2010, 62, 59-82.

5. Grenha, A.; Al-Qadi, S.; Seijo, B.; Remuñán-López, C. The potential of chitosan for pulmonary drug delivery. J. Drug Deliv. Sci. Technol. 2010, 20, 33-43.

6. Lehr, C.-M.; Bouwstra, J.A.; Schacht, E.H.; Junginger, H.E. In vitro evaluation of mucoadhesive properties of chitosan and some other natural polymers. Int. J. Pharm. 1992, 78, 43-48.

7. Deacon, M.P.; McGurk, S.; Roberts, C.J.; Williams, P.M.; Tendler, S.J.; Davies, M.C.; Davis, S.S.; Harding, S.E. Atomic force microscopy of gastric mucin and chitosan mucoadhesive systems. Biochem. J. 2000, 348, 557-563.

8. Shruti, C.; Saiqa, M.; Jasjeet, K.; Zeemat, I.; Sushma, T. Advances and potential applications of chitosan derivatives as mucoadhesive biomaterials in modern drug delivery. J. Pharm. Pharm. 2006, 58, 1021-1032.

9. Kumar, M.N.; Muzzarelli, R.A.; Muzzarelli, C.; Sashiwa, H.; Domb, A.J. Chitosan chemistry and pharmaceutical perspectives. Chem. Rev. 2004, 104, 6017-6084.

10. Baldrick, P. The safety of chitosan as a pharmaceutical excipient. Regul. Toxicol. Pharm. 2010, 56, 290-299. 
11. Braz, L.; Rodrigues, S.; Fonte, P.; Grenha, A.; Sarmento, B. Mechanisms of chemical and enzymatic chitosan biodegradability and its application on drug delivery. In Biodegradable Polymers: Processing, Degradation and Applications; Felton, G., Ed.; Nova Science Publisher: New York, NY, USA, 2011.

12. Dash, M.; Chiellini, F.; Ottenbrite, R.M.; Chiellini, E. Chitosan-A versatile semi-synthetic polymer in biomedical applications. Prog. Polym. Sci. 2011, 36, 981-1014.

13. Rinaudo, M. Main properties and current applications of some polysaccharides as biomaterials. Polym. Int. 2008, 57, 397-430.

14. Rodrigues, S.; Rosa da Costa, A.; Grenha, A. Chitosan/carrageenan nanoparticles: Effect of cross-linking with tripolyphosphate and charge ratios. Carbohydr. Polym. 2012, 89, 282-289.

15. Kurita, K. Chitin and chitosan: Functional biopolymers from marine crustaceans. Mar. Biotechnol. 2006, 8, 203-226.

16. Kean, T.; Thanou, M. Biodegradation, biodistribution and toxicity of chitosan. Adv. Drug Deliv. Rev. 2010, 62, 3-11.

17. Singh, D.; Ray, A. Biomedical applications of chitin, chitosan and their derivatives. Rev. Macromol. Chem. Phys. 2000, C40, 69-83.

18. Cho, Y.; Jang, J.; Park, C.; Ko, S. Preparation and solubility in acid and water of partially deacetylated chitins. Biomacromolecules 2000, 1, 609-614.

19. Prego, C.; Torres, D.; Alonso, M.J. The potential of chitosan for the oral administration of peptides. Expert Opin. Drug Deliv. 2005, 2, 843-854.

20. Şenel, S. Potential applications of chitosan in oral mucosal delivery. J. Drug Deliv. Sci. Technol. 2010, 20, 23-32.

21. Wang, J.J.; Zeng, Z.W.; Xiao, R.Z.; Xie, T.A.; Zhou, G.L.; Zhan, X.R.; Wang, S.L. Recent advances of chitosan nanoparticles as drug carriers. Int. J. Nanomed. 2011, 6, 765-774.

22. Andrade, F.; Antunes, F.; Nascimento, A.; da Silva, S.; das Neves, J.; Ferreira, D.; Sarmento, B. Chitosan formulations as carriers for therapeutic proteins. Curr. Drug Discov. Technol. 2011, 8, 157-172.

23. Park, J.H.; Saravanakumar, G.; Kim, K.; Kwon, I.C. Targeted delivery of low molecular drugs using chitosan and its derivatives. Adv. Drug Deliv. Rev. 2010, 62, 28-41.

24. Chiellini, F.; Piras, A.M.; Errico, C.; Chiellini, E. Micro/nanostructured polymeric systems for biomedical and pharmaceutical applications. Nanomedicine 2008, 3, 367-393.

25. Csaba, N.; Garcia-Fuentes, M.; Alonso, M.J. The performance of nanocarriers for transmucosal drug delivery. Expert Opin. Drug Deliv. 2006, 3, 463-478.

26. Fonte, P.; Andrade, F.; Araújo, F.; Andrade, C.; Neves, Jd.; Sarmento, B. Chitosan-coated solid lipid nanoparticles for insulin delivery. Methods Enzymol. 2012, 508, 295-314.

27. Grenha, A. Chitosan nanoparticles: a survey of preparation methods. J. Drug Target. 2012, 20, 291-300.

28. El-Sherbiny, I.M.; Smyth, H.D.C. Controlled release pulmonary administration of curcumin using swellable biocompatible microparticles. Mol. Pharm. 2011, 9, 269-280. 
29. Venishetty, V.K.; Chede, R.; Komuravelli, R.; Adepu, L.; Sistla, R.; Diwan, P.V. Design and evaluation of polymer coated carvedilol loaded solid lipid nanoparticles to improve the oral bioavailability: A novel strategy to avoid intraduodenal administration. Colloids Surf. B Biointerfaces 2012, 95, 1-9.

30. Zhang, X.; Sun, M.; Zheng, A.; Cao, D.; Bi, Y.; Sun, J. Preparation and characterization of insulin-loaded bioadhesive PLGA nanoparticles for oral administration. Eur. J. Pharm.Sci. 2012, 45, 632-638.

31. Wang, G.; Pan, L.; Zhang, Y.; Wang, Y.; Zhang, Z.; Lü, J.; Zhou, P.; Fang, Y.; Jiang, S. Intranasal delivery of cationic PLGA nano/microparticles-loaded FMDV DNA vaccine encoding IL-6 elicited protective immunity against FMDV challenge. PLoS One 2011, 6, e27605.

32. Pawar, D.; Goyal, A.; Mangal, S.; Mishra, N.; Vaidya, B.; Tiwari, S.; Jain, A.; Vyas, S. Evaluation of mucoadhesive PLGA microparticles for nasal immunization. AAPS J. 2010, 12, $130-137$.

33. Qiang, F.; Shin, H.-J.; Lee, B.-J.; Han, H.-K. Enhanced systemic exposure of fexofenadine via the intranasal administration of chitosan-coated liposome. Int. J. Pharm. 2012, 430, 161-166.

34. Sugihara, H.; Yamamoto, H.; Kawashima, Y.; Takeuchi, H. Effectiveness of submicronized chitosan-coated liposomes in oral absorption of indomethacin. J. Liposome Res.2012, 22, 72-79.

35. Fernández-Urrusuno, R.; Calvo, P.; Remuñán-López, C.; Vila-Jato, J.L.; José Alonso, M. Enhancement of nasal absorption of insulin using chitosan nanoparticles. Pharm. Res. 1999, 16, $1576-1581$.

36. Vila, A.; Sánchez, A.; Janes, K.; Behrens, I.; Kissel, T.; Jato, J.L. V.; Alonso, M.J. Low molecular weight chitosan nanoparticles as new carriers for nasal vaccine delivery in mice. Eur. J. Pharm. Biopharm. 2004, 57, 123-131.

37. Artursson, P.; Lindmark, T.; Davis, S.S.; Illum, L. Effect of chitosan on the permeability of monolayers of intestinal epithelial cells (Caco-2). Pharm. Res. 1994, 11, 1358-1361.

38. Borchard, G.; Lueßen, H.L.; de Boer, A.G.; Verhoef, J.C.; Lehr, C.-M.; Junginger, H.E. The potential of mucoadhesive polymers in enhancing intestinal peptide drug absorption. III: Effects of chitosan-glutamate and carbomer on epithelial tight junctions in vitro. J. Control. Release 1996, 39, 131-138.

39. Prego, C.; García, M.; Torres, D.; Alonso, M.J. Transmucosal macromolecular drug delivery. J. Control. Release 2005, 101, 151-162.

40. De Campos, A.M.; Sánchez, A.; Alonso, M.J. Chitosan nanoparticles: A new vehicle for the improvement of the delivery of drugs to the ocular surface. Application to cyclosporin A. Int. J. Pharm. 2001, 224, 159-168.

41. Portero, A.; Remuñán-López, C.; Nielsen, H.M. The potential of chitosan in enhancing peptide and protein absorption across the TR146 cell culture model-An in vitro model of the buccal epithelium. Pharm. Res. 2002, 19, 169-174.

42. Al-Qadi, S.; Grenha, A.; Carrión-Recio, D.; Seijo, B.; Remuñán-López, C. Microencapsulated chitosan nanoparticles for pulmonary protein delivery: In vivo evaluation of insulin-loaded formulations. J. Control. Release 2012, 157, 383-390.

43. Arca, H. C.; Gunbeyaz, M.; Senel, S. Chitosan-based systems for the delivery of vaccine antigens. Expert Rev. Vaccines 2009, 8, 937-953. 
44. Jarmila, V.; Vavríková, E. Chitosan derivatives with antimicrobial, antitumour and antioxidant activities - A review. Curr. Pharm.Design 2011, 17, 3596-3607.

45. Zhang, J.; Xia, W.; Liu, P.; Cheng, Q.; Tahirou, T.; Gu, W.; Li, B. Chitosan modification and pharmaceutical/biomedical applications. Mar. Drugs 2010, 8, 1962-1987.

46. Ren, D.; Yi, H.; Wang, W.; Ma, X. The enzymatic degradation and swelling properties of chitosan matrices with different degrees of N-acetylation. Carbohydr. Res. 2005, 340, 2403-2410.

47. Aillon, K.L.; Xie, Y.; El-Gendy, N.; Berkland, C.J.; Forrest, M.L. Effects of nanomaterial physicochemical properties on in vivo toxicity. Adv. Drug Deliv. Rev. 2009, 61, 457-466.

48. Hirano, S.; Tsuchida, H.; Nagao, N. N-acetylation in chitosan and the rate of its enzymic hydrolysis. Biomaterials 1989, 10, 574-576.

49. Aiba, S. Studies on chitosan: 4. Lysozymic hydrolysis of partially N-acetylated chitosans. Int. J. Biol. Macromol. 1992, 14, 225-228.

50. Pangburn, S.; Trescony, P.; Heller, J. Lysozyme degradation of partially deacetylated chitin, its films and hydrogels. Biomaterials 1982, 3, 105-108.

51. Kofuji, K.; Qian, C.; Nishimura, M.; Sugiyama, I.; Murata, Y.; Kawashima, S. Relationship between physicochemical characteristics and functional properties of chitosan. Eur. Polym. J. 2005, 41, 2784-2791.

52. Schipper, N.G.M.; Vårum, K.M.; Artursson, P. Chitosans as absorption enhancers for poorly absorbable drugs. 1: Influence of molecular weight and degree of acetylation on drug transport across human intestinal epithelial (Caco-2) cells. Pharm. Res. 1996, 13, 1686-1692.

53. Gaspar, R.; Duncan, R. Polymeric carriers: Preclinical safety and the regulatory implications for design and development of polymer therapeutics. Adv. Drug Deliv. Rev. 2009, 61, 1220-1231.

54. Williams, D. Definitions in Biomaterials; Elsevier: Amsterdam, The Netherlands, 1987.

55. Williams, D.F. On the mechanisms of biocompatibility. Biomaterials 2008, 29, 2941-2953.

56. Power, K.A.; Fitzgerald, K.T.; Gallagher, W.M. Examination of cell-host-biomaterial interactions via high-throughput technologies: A re-appraisal. Biomaterials 2010, 31, 6667-6674.

57. Kohane, D.; Langer, R. Biocompatibility and drug delivery systems. Chem. Sci. 2010, 1, 441-446.

58. Guyton, A.; Hall, J. Textbook of Medical Physiology, 12th ed.; Elsevier: Philadelphia, PA, USA, 2011.

59. Sahay, G.; Alakhova, D.Y.; Kabanov, A.V. Endocytosis of nanomedicines. J. Control. Release 2010, 145, 182-195.

60. Huang, M.; Khor, E.; Lim, L.-Y. Uptake and cytotoxicity of chitosan molecules and nanoparticles: Effects of molecular weight and degree of deacetylation. Pharm. Res. 2004, 21, 344-353.

61. ISO. Biological Evaluation of Medical Devices Part 5: Tests for in vitro Cytotoxicity, 10993-5: 2009; International Organization for Standardization: Geneva, Switzerland, 2009.

62. ISO. Biological Evaluation of Medical Devices Part 1: Evaluation and Testing, 10993-1: 2009; International Organization for Standardization: Geneva, Switzerland, 2009.

63. ISO. Biological Evaluation of Medical Devices Part 3: Tests for Genotoxicity, Carcinogenicity, and Reproductive Toxicity, 10993-3: 2003, International Organization for Standardization: Geneva, Switzerland, 2003.

64. Lewinski, N.; Colvin, V.; Drezek, R. Cytotoxicity of nanoparticles. Small 2008, 4, 26-49. 
65. Keong, L.; Halim, A. In vitro models in biocompatibility assessment for biomedical-grade chitosan derivatives in wound management. Int. J. Mol. Sci. 2009, 10, 1300-1313.

66. ISO. Biological Evaluation of Medical Devices Part 2: Animal Welfare Requirements, 10993-2: 2006; International Organization for Standardization: Geneva, Switzerland, 2006.

67. Scherlie $\beta$, R. The MTT assay as tool to evaluate and compare excipient toxicity in vitro on respiratory epithelial cells. Int. J. Pharm. 2011, 411, 98-105.

68. Oh, H.; Livingston, R.; Smith, K.; Abrishamian-Garcia, L. Comparative study of the time dependency of cell death assays. MIT Undergrad. Res. J. 2004, 11, 53-62.

69. Altman, S.A.; Randers, L.; Rao, G. Comparison of trypan blue dye exclusion and fluorometric assays for mammalian cell viability determinations. Biotechnol. Prog. 1993, 9, 671-674.

70. Soenen, S.; de Cuyper, M. Assessing cytotoxicity of (iron oxide-based) nanoparticles: An overview of different methods exemplified with cationic magnetoliposomes. Contrast Media Mol. Imaging 2009, 4, 207-219.

71. Monteiro-Riviere, N.A.; Inman, A.O.; Zhang, L.W. Limitations and relative utility of screening assays to assess engineered nanoparticle toxicity in a human cell line. Toxicol. Appl. Pharm. 2009, 234, 222-235.

72. Stoddart, M.J. Cell viability assays: Introduction. Methods Mol. Biol. 2011, 740, 1-6.

73. King, M.A. Detection of dead cells and measurement of cell killing by flow cytometry. J. Immunol. Methods 2000, 243, 155-166.

74. Aden, P.; Goverud, I.; Liestøl, K.; Løberg, E.M.; Paulsen, R.E.; Mæhlen, J.; Lømo, J. Low-potency glucocorticoid hydrocortisone has similar neurotoxic effects as high-potency glucocorticoid dexamethasone on neurons in the immature chicken cerebellum. Brain Res. 2008, 1236, 39-48.

75. Han, X.; Gelein, R.; Corson, N.; Wade-Mercer, P.; Jiang, J.; Biswas, P.; Finkelstein, J.N.; Elder, A.; Oberdörster, G. Validation of an LDH assay for assessing nanoparticle toxicity. Toxicology 2011, 287, 99-104.

76. Fotakis, G.; Timbrell, J.A. In vitro cytotoxicity assays: Comparison of LDH, neutral red, MTT and protein assay in hepatoma cell lines following exposure to cadmium chloride. Toxicol. Lett. 2006, 160, 171-177.

77. Racher, A.J.; Looby, D.; Griffiths, J.B. Use of lactate dehydrogenase release to assess changes in culture viability. Cytotechnology 1990, 3, 301-307.

78. Zhao, C.; Li, X.; Luo, S.; Chang, Y. Assessments of lysosomal membrane responses to stresses with neutral red retention assay and its potential application in the improvement of bivalve aquaculture. Afr. J. Biotechnol. 2011, 10, 13968-13973.

79. Hamid, R.; Rotshteyn, Y.; Rabadi, L.; Parikh, R.; Bullock, P. Comparison of alamar blue and MTT assays for high through-put screening. Toxicol. in Vitro 2004, 18, 703-710.

80. Gonzalez, R.J.; Tarloff, J.B. Evaluation of hepatic subcellular fractions for Alamar blue and MTT reductase activity. Toxicol. in Vitro 2001, 15, 257-259.

81. Bernas, T.; Dobrucki, J. Mitochondrial and nonmitochondrial reduction of MTT: Interaction of MTT with TMRE, JC-1, and NAO mitochondrial fluorescent probes. Cytometry 2002, 47, 236-242.

82. Jena, P.; Mohanty, S.; Mallick, R.; Jacob, B.; Sonawane, A. Toxicity and antibacterial assessment of chitosancoated silver nanoparticles on human pathogens and macrophage cells. Int. J. Nanomed. 2012, 7, 1805-1818. 
83. Xu, J.; Ma, L.; Liu, Y.; Xu, F.; Nie, J.; Ma, G. Design and characterization of antitumor drug paclitaxel-loaded chitosan nanoparticles by W/O emulsions. Int. J. Biol. Macromol. 2012, 50, $438-443$.

84. Grenha, A.; Gomes, M.E.; Rodrigues, M.; Santo, V.E.; Mano, J.F.; Neves, N.M.; Reis, R.L. Development of new chitosan/carrageenan nanoparticles for drug delivery applications. J. Biomed. Mater. Res. Part A 2010, 92A, 1265-1272.

85. Jeong, Y.-I.; Jin, S.-G.; Kim, I.-Y.; Pei, J.; Wen, M.; Jung, T.-Y.; Moon, K.-S.; Jung, S. Doxorubicin-incorporated nanoparticles composed of poly(ethylene glycol)-grafted carboxymethyl chitosan and antitumor activity against glioma cells in vitro. Colloids Surf. B Biointerf. 2010, 79, 149-155.

86. Anitha, A.; Chennazhi, K.; Nair, S.; Jayakumar, R. 5-flourouracil loaded N,O-carboxymethyl chitosan nanoparticles as an anticancer nanomedicine for breast cancer. J. Biomed. Nanotechnol. 2012, 8, 29-42.

87. Silva, C.M.; Veiga, F.; Ribeiro, A.J.; Zerrouk, N.; Arnaud, P. Effect of chitosan-coated alginate microspheres on the permeability of Caco-2 cell monolayers. Drug Dev. Ind. Pharm. 2006, 32, 1079-1088.

88. Huang, R.; Mendis, E.; Rajapakse, N.; Kim, S.-K. Strong electronic charge as an important factor for anticancer activity of chitooligosaccharides (COS). Life Sci. 2006, 78, 2399-2408.

89. Kowapradit, J.; Opanasopit, P.; Ngawhirunpat, T.; Apirakaramwong, A.; Rojanarata, T.; Ruktanonchai, U.; Sajomsang, W. In vitro permeability enhancement in intestinal epithelial cells (Caco-2) monolayer of water soluble quaternary ammonium chitosan derivatives. AAPS PharmSciTech 2010, 11, 497-508.

90. Loh, J.W.; Yeoh, G.; Saunders, M.; Lim, L.-Y. Uptake and cytotoxicity of chitosan nanoparticles in human liver cells. Toxicol. Appl. Pharm. 2010, 249, 148-157.

91. Grenha, A.; Grainger, C.I.; Dailey, L.A.; Seijo, B.; Martin, G.P.; Remuñán-López, C.; Forbes, B. Chitosan nanoparticles are compatible with respiratory epithelial cells in vitro. Eur. J. Pharm. Sci. 2007, 31, 73-84.

92. Lozano, M.V.; Torrecilla, D.; Torres, D.; Vidal, A.; Dominguez, F.; Alonso, M.J. Highly efficient system to deliver taxanes into tumor cells: Docetaxel-loaded chitosan oligomer colloidal carriers. Biomacromolecules 2008, 9, 2186-2193.

93. Zaki, N.; Hafez, M. Enhanced antibacterial effect of ceftriaxone sodium-loaded chitosan nanoparticles against intracellular Salmonella typhimurium. AAPS PharmSciTech 2012, 13, 411-421.

94. Wang, Z.H.; Wang, Z.Y.; Sun, C.S.; Wang, C.Y.; Jiang, T.Y.; Wang, S.L. Trimethylated chitosan-conjugated PLGA nanoparticles for the delivery of drugs to the brain. Biomaterials 2010, 31, 908-915.

95. Guerra, G.D.; Cerrai, P.; Tricoli, M.; Maltinti, S.; Guerra, R.S.D. In vitro cytotoxicity testing of chitosan-containing polyelectrolyte complexes. J. Mater. Sci. Mater. Med. 1998, 9, 73-76.

96. Mura, S.; Hillaireau, H.; Nicolas, J.; Le Droumaguet, B.; Gueutin, C.; Zanna, S.; Tsapis, N.; Fattal, E. Influence of surface charge on the potential toxicity of PLGA nanoparticles towards Calu-3 cells. Int. J. Nanomed. 2011, 6, 2591-2605. 
97. Chang, S.; Kang, B.; Dai, Y.; Zhang, H.; Chen, D. One-step fabrication of biocompatible chitosan-coated $\mathrm{ZnS}$ and $\mathrm{ZnS}: \mathrm{Mn} 2+$ quantum dots via a $\gamma$-radiation route. Nanoscale Res. Lett. 2011, 6, 591-597.

98. Tan, W.B.; Zhang, Y. Surface modification of gold and quantum dot nanoparticles with chitosan for bioapplications. J. Biomed. Mater. Res. Part A 2005, 75A, 56-62.

99. Woitiski, C.B.; Sarmento, B.; Carvalho, R.A.; Neufeld, R.J.; Veiga, F. Facilitated nanoscale delivery of insulin across intestinal membrane models. Int. J. Pharm. 2011, 412, 123-131.

100. Shu, S.; Zhang, X.; Teng, D.; Wang, Z.; Li, C. Polyelectrolyte nanoparticles based on water-soluble chitosan-poly(1-aspartic acid)-polyethylene glycol for controlled protein release. Carbohyd. Res. 2009, 344, 1197-1204.

101. Nafee, N.; Schneider, M.; Schaefer, U.F.; Lehr, C.-M. Relevance of the colloidal stability of chitosan/PLGA nanoparticles on their cytotoxicity profile. Int. J. Pharma. 2009, 381, 130-139.

102. Weyermann, J.; Lochmann, D.; Zimmer, A. A practical note on the use of cytotoxicity assays. Int. J. Pharm. 2005, 288, 369-376.

103. Smith, J.; Wood, E.; Dornish, M. Effect of chitosan on epithelial cell tight junctions. Pharm. Res. 2004, 21, 43-49.

104. Ulluwishewa, D.; Anderson, R.C.; McNabb, W.C.; Moughan, P.J.; Wells, J.M.; Roy, N.C. Regulation of tight junction permeability by intestinal bacteria and dietary components. J. Nut. 2011, 141, 769-776.

105. Johnson, P.H.; Frank, D.; Costantino, H.R. Discovery of tight junction modulators: Significance for drug development and delivery. Drug Discov. Today 2008, 13, 261-267.

106. Salama, N.N.; Eddington, N.D.; Fasano, A. Tight junction modulation and its relationship to drug delivery. Adv. Drug Deliv. Rev. 2006, 58, 15-28.

107. Pasternak, A.S.; Miller, W.M. Measurement of trans-epithelial electrical resistance in perfusion: Potential application for in vitro ocular toxicity testing. Biotechnol. Bioeng. 1996, 50, 568-579.

108. Schneeberger, E.E.; Lynch, R.D. The tight junction: a multifunctional complex. Am. J. Physiol. Cell Physiol. 2004, 286, C1213-C1228.

109. Stewart, C.; Torr, E.; Jamili, N.; Bosquillon, C.; Sayers, I. Evaluation of differentiated human bronchial epithelial cell culture systems for asthma research. J. Allergy 2012, 2012, 1-11.

110. Forbes, B.; Hashmi, N.; Martin, G.; Lansley, A. Formulation of inhaled medicines: Effect of delivery vehicle on immortalized epithelial cells. J. Aerosol Med. 2000, 13, 281-288.

111. Van der Lubben, I.M.; Verhoef, J.C.; Borchard, G.; Junginger, H.E. Chitosan and its derivatives in mucosal drug and vaccine delivery. Eur. J. Pharm. Sci. 2001, 14, 201-207.

112. González-Mariscal, L.; Nava, P.; Hernández, S. Critical role of tight junctions in drug delivery across epithelial and endothelial cell layers. J. Membr. Biol. 2005, 207, 55-68.

113. Gonzalez-Mariscal, L.; Hernández, S.; Vega, J. Inventions designed to enhance drug delivery across epithelial and endothelial cells through the paracellular pathway. Recent Pat. Drug Deliv. Formul. 2008, 2, 145-176.

114. Vllasaliu, D.; Exposito-Harris, R.; Heras, A.; Casettari, L.; Garnett, M.; Illum, L.; Stolnik, S. Tight junction modulation by chitosan nanoparticles: Comparison with chitosan solution. Int. J. Pharm. 2010, 400, 183-193. 
115. Teijeiro-Osorio, D.; Remuñán-López, C.; Alonso, M.J. New generation of hybrid poly/oligosaccharide nanoparticles as carriers for the nasal delivery of macromolecules. Biomacromolecules 2009, 10, 243-249.

116. Loh, J.W.; Saunders, M.; Lim, L.-Y. Cytotoxicity of monodispersed chitosan nanoparticles against the Caco-2 cells. Toxicol. Appl. Pharm. 2012, 262, 273-282.

117. Sadeghi, A.M.M.; Dorkoosh, F.A.; Avadi, M.R.; Weinhold, M.; Bayat, A.; Delie, F.; Gurny, R.; Larijani, B.; Rafiee-Tehrani, M.; Junginger, H.E. Permeation enhancer effect of chitosan and chitosan derivatives: Comparison of formulations as soluble polymers and nanoparticulate systems on insulin absorption in Caco-2 cells. Eur. J. Pharm. Biopharm. 2008, 70, 270-278.

118. Ma, Z.; Lim, L.-Y. Uptake of chitosan and associated insulin in Caco-2 cell monolayers: A comparison between chitosan molecules and chitosan nanoparticles. Pharma. Res. 2003, 20, $1812-1819$.

119. Olive, P.L. The comet assay: An overview of techniques. In In Situ Detection of DNA Damage: Methods and Protocols; Didenko, V.V., Ed.; Humana Press: Totowa, NJ, USA, 2002; Volume 203, pp. 179-194.

120. Fernandes, J.C.; Borges, M.; Nascimento, H.; Bronze-da-Rocha, E.; Ramos, O.S.; Pintado, M.E.; Malcata, F.X.; Santos-Silva, A. Cytotoxicity and genotoxicity of chitooligosaccharides upon lymphocytes. Int. J. Biol. Macromol. 2011, 49, 433-438.

121. Lewis, C.; McGee, J.D. The Macrophage; IRL Press: Oxford, UK, 1992; p. 423.

122. Liu, L.; Song, C.; Song, L.; Zhang, H.; Dong, X.; Leng, X. Effects of alkylated-chitosan-DNA nanoparticles on the function of macrophages. J. Mater. Sci. Mater. Med. 2009, 20, 943-948.

123. Zhang, C.; Qu, G.; Sun, Y.; Wu, X.; Yao, Z.; Guo, Q.; Ding, Q.; Yuan, S.; Shen, Z.; Ping, Q.; Zhou, H. Pharmacokinetics, biodistribution, efficacy and safety of N-octyl-O-sulfate chitosan micelles loaded with paclitaxel. Biomaterials 2008, 29, 1233-1241.

124. Jiang, H.-L.; Lim, H.-T.; Kim, Y.-K.; Arote, R.; Shin, J.-Y.; Kwon, J.-T.; Kim, J.-E.; Kim, J.-H.; Kim, D.; Chae, C.; Nah, J.-W.; Choi, Y.-J.; Cho, C.-S.; Cho, M.-H. Chitosan-graft-spermine as a gene carrier in vitro and in vivo. Eur. J. Pharm. Biopharm. 2011, 77, 36-42.

125. Choi, M.; Cho, M.; Han, B.S.; Hong, J.; Jeong, J.; Park, S.; Cho, M.-H.; Kim, K.; Cho, W.-S. Chitosan nanoparticles show rapid extrapulmonary tissue distribution and excretion with mild pulmonary inflammation to mice. Toxicol. Lett. 2010, 199, 144-152.

126. Huang, Y.C.; Vieira, A.; Huang, K.L.; Yeh, M.K.; Chiang, C.H. Pulmonary inflammation caused by chitosan microparticles. J. Biomed. Mater. Res. Part A 2005, 75, 283-287.

127. Pandey, R.; Khuller, G.K. Chemotherapeutic potential of alginate-chitosan microspheres as anti-tubercular drug carriers. J. Antimicrob. Chemother. 2004, 53, 635-640.

128. Sonaje, K.; Lin, Y.H.; Juang, J.H.; Wey, S.P.; Chen, C.T.; Sung, H.W. In vivo evaluation of safety and efficacy of self-assembled nanoparticles for oral insulin delivery. Biomaterials 2009, 30, 2329-2339.

129. Sonaje, K.; Lin, K.-J.; Tseng, M.T.; Wey, S.-P.; Su, F.-Y.; Chuang, E.-Y.; Hsu, C.-W.; Chen, C.-T.; Sung, H.-W. Effects of chitosan-nanoparticle-mediated tight junction opening on the oral absorption of endotoxins. Biomaterials 2011, 32, 8712-8721. 
130. Zheng, F.; Shi, X.-W.; Yang, G.-F.; Gong, L.-L.; Yuan, H.-Y.; Cui, Y.-J.; Wang, Y.; Du, Y.-M.; $\mathrm{Li}, \mathrm{Y}$. Chitosan nanoparticle as gene therapy vector via gastrointestinal mucosa administration: Results of an in vitro and in vivo study. Life Sci. 2007, 80, 388-396.

131. Semete, B.; Booysen, L.I.J.; Kalombo, L.; Venter, J.D.; Katata, L.; Ramalapa, B.; Verschoor, J.A.; Swai, H. In vivo uptake and acute immune response to orally administered chitosan and PEG coated PLGA nanoparticles. Toxicol. Appl. Pharm. 2010, 249, 158-165.

132. Pokharkar, V.; Dhar, S.; Bhumkar, D.; Mali, V.; Bodhankar, S.; Prasad, B.L.V. Acute and subacute toxicity studies of chitosan reduced gold nanoparticles: A novel carrier for therapeutic agents. J. Biomed. Nanotechnol. 2009, 5, 233-239.

133. Kunzmann, A.; Andersson, B.; Thurnherr, T.; Krug, H.; Scheynius, A.; Fadeel, B. Toxicology of engineered nanomaterials: Focus on biocompatibility, biodistribution and biodegradation. Biochim. Biophys. Acta 2011, 1810, 361-373.

134. Chen, X.-G.; Liu, C.-S.; Liu, C.-G.; Meng, X.-H.; Lee, C.M.; Park, H.-J. Preparation and biocompatibility of chitosan microcarriers as biomaterial. Biochem. Eng. J. 2006, 27, 269-274.

(C) 2012 by the authors; licensee MDPI, Basel, Switzerland. This article is an open access article distributed under the terms and conditions of the Creative Commons Attribution license (http://creativecommons.org/licenses/by/3.0/). 